\title{
Acute coronary syndrome and acute kidney injury: role of inflammation in worsening renal function
}

\author{
Jorge Ortega-Hernández ${ }^{1,2}$, Rashidi Springall1, Fausto Sánchez-Muñoz ${ }^{1}$, Julio-C. Arana-Martinez ${ }^{1,3}$,
} Héctor González-Pacheco ${ }^{4}$ and Rafael Bojalil ${ }^{1,3^{*}}$ (1)

\begin{abstract}
Background: Acute Kidney Injury (AKI), a common complication of acute coronary syndromes (ACS), is associated with higher mortality and longer hospital stays. The role of cytokines and other mediators is unknown in AKI induced by an ACS (ACS-AKI), leading to several unanswered questions. The worsening of renal function is usually seen as a dichotomous phenomenon instead of a dynamic change, so evaluating changes of the renal function in time may provide valuable information in the ACS-AKI setting. The aim of this study was to explore inflammatory factors associated to de novo kidney injury induced by de novo cardiac injury secondary to ACS.

Methods: One hundred four consecutive patients with ACS were initially included on the time of admission to the Coronary Unit of the Instituto Nacional de Cardiología in Mexico City, from February to May 2016, before any invasive procedure, imaging study, diuretic or anti-platelet therapy. White blood count, hemoglobin, NT-ProBNP, troponin I, C-reactive protein, albumin, glucose, $\mathrm{Na}^{+}, \mathrm{K}^{+}$, blood urea nitrogen (BUN), total cholesterol, $\mathrm{HDL}, \mathrm{LDL}$, triglycerides, creatinine (Cr), endothelin-1 (ET-1), leukotriene-B4, matrix metalloproteinase-2 and -9, tissue inhibitor of metalloproteinases-1, resolvin-D1 (RvD1), lipoxin-A4 (LXA4), interleukin-1 $\beta,-6,-8$, and -10 were measured. We finally enrolled 78 patients, and subsequently we identified 15 patients with ACS-AKI. Correlations were obtained by a Spearman rank test. Low-rank regression, splines regressions, and also protein-protein/chemical interactions and pathways analyses networks were performed.
\end{abstract}

Results: Positive correlations of $\Delta C r$ were found with BUN, admission Cr, GRACE score, IL-1 $\beta$, IL-6, NT-ProBNP and age, and negative correlations with systolic blood pressure, mean-BP, diastolic-BP and LXA4. In the regression analyses IL-10 and RvD1 had positive non-linear associations with $\Delta \mathrm{Cr}$. ET-1 had also a positive association. Significant non-linear associations were seen with NT-proBNP, admission $\mathrm{Cr}, \mathrm{BUN}, \mathrm{Na}^{+}, \mathrm{K}^{+}, \mathrm{WBC}$, age, body mass index, GRACE, SBP, mean-BP and Hb.

Conclusion: Inflammation and its components play an important role in the worsening of renal function in ACS. IL-10, ET-1, IL-1 $\beta$, Tnl, RvD1 and LXA4 represent mediators that might be associated with ACS-AKI. IL-6, ET-1, NTProBNP might represent crossroads for several physiopathological pathways involved in "de novo cardiac injury leading to de novo kidney injury".

Keywords: Acute coronary syndrome, Acute renal injury, Cardiorenal crosstalk, Inflammation, Cytokines, Lipid mediators

\footnotetext{
* Correspondence: rafaelbojalil@gmail.com

'Department of Immunology, Instituto Nacional de Cardiología Ignacio

Chávez, Juan Badiano 1, Sección XVI, Tlalpan, 14080 Mexico City, Mexico

${ }^{3}$ Department of Health Care, Universidad Autónoma Metropolitana

Xochimilco, Calzada del Hueso 1100, Villa Quietud, Coyoacán, 04960 Mexico

City, Mexico

Full list of author information is available at the end of the article
} International License (http://creativecommons.org/licenses/by/4.0/), which permits unrestricted use, distribution, and reproduction in any medium, provided you give appropriate credit to the original author(s) and the source, provide a link to the Creative Commons license, and indicate if changes were made. The Creative Commons Public Domain Dedication waiver (http://creativecommons.org/publicdomain/zero/1.0/) applies to the data made available in this article, unless otherwise stated. 


\section{Background}

Acute Kidney Injury (AKI) is a common complication of acute coronary syndromes, and its ultimate expression is the cardiorenal syndrome (CRS) type 1, defined "as an acute worsening of heart function leading to AKI or dysfunction" that is a complication of "acute heart failure (AHF) and/or acute coronary syndrome (ACS)", associated with a high risk mortality and longer hospital stay [1-3].

The heart-kidney axis is complex and usually ill-defined [2]. Complex pathways exist regarding cardiorenal crosstalk; these can be broadly grouped in hemodynamic, hormonal, inflammatory and of immune signaling [4]. Still, the interactions and mechanisms are poorly understood to the point that it has been suggested that the cardiac index in heart failure is not the primary driver of renal dysfunction, leaving the door open to alternative pathways to be explored [5].

The role of various inflammatory mediators has not been fully studied in ACS-AKI [6-8]. A clear example is endothelin-1 (ET-1) that despite its pleiotropic role in endothelial and glomerular dynamics $[9,10]$ has not been studied. There is also a lack of knowledge of the role of lipid mediators regarding the cardio-renal cross talk, although it has been suggested that specialized proresolving lipid mediators (SPMs) such as resolvins (Rv) and lipoxins (Lx) confer protection and repair in experimental models of AKI and myocardial infarction, by limiting the fibrosis and halting the inflammation [11, 12].

Hence, the role of cytokines and mediators is unknown in AKI specifically in the context of ACS, leading to several unanswered questions. Furthermore the worsening renal function is usually seen as a dichotomous phenomenon instead of a dynamic change in the target organ, the kidney, and evaluating the declining kidney's function may provide more valuable information in the ACS-AKI setting [13].

\section{Methods}

Aim

The aim of this study was to explore inflammatory factors associated to de novo kidney injury in patients with de novo cardiac injury secondary to ACS.

\section{Study population}

One hundred four consecutive patients were initially included at the time of arrival to the coronary unit of the Instituto Nacional de Cardiología Ignacio Chavez, in Mexico City with ST-elevation myocardial infarction (STEMI) or non-ST elevation acute coronary syndrome (NSTE-ACS), $\geq 18$ years of age and $<24 \mathrm{~h}$ of the initial symptom, from February to May 2016. All patients' records were thoroughly examined and reviewed until the patient discharge or dismissal. We enrolled 78 patients, and subsequently we identified 15 patients with ACSAKI. Seventeen healthy volunteers were included as controls for the serum lipid mediators' analysis (see Additional file 1: Table S1).

STEMI, NSTE-ACS and key data elements and definitions were defined according to the AHA/ACC guidelines [14-16]. AKI was defined based on serum creatinine $(\mathrm{Cr})$ as stated by the KDIGO guidelines [17]. Delta $\mathrm{Cr}(\Delta \mathrm{Cr})$ was obtained by the subtraction of the baseline value to the admission value. Baseline $\mathrm{Cr}$ was defined as the lowest $\mathrm{Cr}$ during hospitalization, maintained for more than $72 \mathrm{~h}$ or until the patient discharge, and that could not be explained by fluid resuscitation, overload or dialysis.

Patients with known pregnancy or in postpartum period, infectious, autoimmune, hepatic, or neoplastic diseases were excluded; as well as patients with current or previous dialysis, transplant, episodes of AHF or chronic heart failure, and previous ACS. Furthermore, patients with a baseline clearance $<55 \mathrm{ml} / \mathrm{kg} / \mathrm{min}^{-1}$ (by 4-variable standardized-MDRD study equations) were also excluded. We eliminated patients that were diagnosed during the study with any of the exclusion criteria, or loss of information occurred at any time of the study.

The study protocol was approved both by the Research Committee and the Ethics in Research Committee of the Instituto Nacional de Cardiología Ignacio Chavez (\#16-971). All patients or their legally authorized representatives provided written informed consent. All procedures were conducted based on the Declaration of Helsinki and local regulations.

\section{Sample obtaining and serum determinations}

Samples were collected on the time of admission before any invasive procedure, imaging study, diuretic or antiplatelet therapy. We obtained between 10 and $20 \mathrm{ml}$ of blood. The serum was centrifuged at $3000 \mathrm{rpm}$ for $25 \mathrm{~min}$, recollected in $500 \mu \mathrm{L}$ vials and stored at $-76{ }^{\circ} \mathrm{C}$ until the serum readings were performed.

White blood count (WBC), hemoglobin (Hb), NT-Pro B-Type-Natriuretic-Peptide (NT-ProBNP), troponin-I (TnI), high-sensitive C-reactive protein (hs-CRP), albumin, glucose, sodium $\left(\mathrm{Na}^{+}\right)$, potassium $\left(\mathrm{K}^{+}\right)$, blood urea nitrogen (BUN), high density lipoprotein (HDL), low density lipoprotein (LDL), total cholesterol (TChol), triglycerides (TG) and creatinine $(\mathrm{Cr})$ levels were performed by the hospital clinical laboratory.

ET-1, leukotriene-B4 (LTB4), matrix metalloproteinase (MMP)-2, MMP-9 and tissue inhibitor of metalloproteinases (TIMP)-1 (R\&D Systems ${ }^{\mathrm{Tn}}$, Inc. Minneapolis, MN, USA), RvD1 (Cayman Chemical Company, Ann Arbor, MI, USA), LXA4 (Cloud-Clone Corp. Houston, TX, USA) were determined by enzyme-linked immunosorbent assays using commercial kits per instructions provided by the manufacturer. 
And for interleukin (IL)-1 $\beta$, IL-6, IL-8, IL-10, multiplex magnetic bead-based antibody detection kits were used per the manufacturer's protocols (Multiplex immunoassay ProcartaPlex ${ }^{\circ}$ Bender, MedSystems GmbH, Campus Vienna Biocenter 2, Vienna, Austria) and read in Luminex ${ }^{\circ}$ MAGPIX (Luminex Corporation, Austin, TX) with software v4.2 (Luminex-xPonent-MAGPIX ${ }^{\circ}$.

\section{Statistical analysis}

Clinical and laboratorial parameters data were expressed as median and interquartile ranges (IQR). The $\mathrm{X}^{2}$ test was used to compare clinical characteristics. Mann-Whitney$\mathrm{U}$ test for group comparisons and Kruskal-Wallis test for multiple group comparison were performed. Also, both correlation and regression analysis were performed. Correlations were obtained by a Spearman rank test [18]. In the regression models, cytokines, Pro-BNP, CRP and $\mathrm{TnI}$ were entered as log-transformed variables to reduce their skew, being $\Delta \mathrm{Cr}$ the outcome variable. We did not perform an analysis based on the presence of AKI since dichotomization can lead to reduced information quality [19]. Low-rank regression splines were specified in the framework of generalized additive models and fitted to penalized likelihood estimation (GAMPL in SAS) to produce flexible nonparametric regressions, and visually asses the relation with the $\Delta \mathrm{Cr}$ changes the degrees of freedom were determined by generalized cross-validation $[20,21]$. The regression models were adjusted to age, sex, diabetes, hypertension history and the type of ACS (STEMI or NSTE-ACS). A $p$ value of $<0.05$ was considered significant. The analysis was done in SPSSv22 and SASUniversity-Edition@.

\section{Protein-protein/chemical interaction and pathway analysis networks}

Protein-protein interaction networks were obtained from the STRING v10.0 [22] database, protein-chemical interaction STITCH v4.0 [23] and v5.0 [24] (both with a required confidence (score) >0.7). Also, MetaCore ${ }^{\mathrm{rx}}$ (Thomson Reuters) public pathways were also fully reviewed for any possible interactions. All interactions were thoroughly reviewed (from the Co-Mentioned in PubMed Abstracts, references or pathways) for averting as far as possible any false positive or negative edges.

\section{Results}

Baseline and laboratorial characteristics in ACS vs ACS-AKI

The median age in the ACS-AKI group was 73 years. $73.3 \%$ were male, 53.3 had diabetes, $73.3 \%$ hypertension, $60 \%$ smoking history, $66.7 \%$ NSTE-ACS and $33.3 \%$ had a fatal outcome during the hospitalization. While in ACS the median age was 58 years, $74.6 \%$ were male, 42.9 had diabetes, $55.6 \%$ hypertension, $65.1 \%$ smoking history and $47.6 \%$ NSTE-ACS and 3.2\% had a fatal outcome. Only age and death were significant between the groups. Moreover, 4 patients in the ACS group developed AKI during their hospitalization, 2 of them had a fatal outcome which added to those from the ACS-AKI group represent the totality of deceases. Systolic blood pressure (SBP) and GRACE were higher in ACS-AKI $(p=0.045$ and 0.002, respectively). NT-ProBNP, BUN, admission $\mathrm{Cr}$ and, and max $\mathrm{Cr}$ during hospitalization, also were higher in the ACS-AKI group (Table 1).

Table 1 Clinical and laboratorial characteristics

\begin{tabular}{|c|c|c|c|}
\hline & ACS & ACS-AKI & $p$ \\
\hline n (\%) & $63(80.7)$ & $15(19.3)$ & \\
\hline Age & $58(51-67)$ & $73(63-78)$ & 0.001 \\
\hline Male (\%) & $47(74.6)$ & $11(73.3)$ & 0.919 \\
\hline DM (\%) & $27(42.9)$ & $8(53.3)$ & 0.463 \\
\hline HTN (\%) & $35(55.6)$ & $11(73.3)$ & 0.136 \\
\hline SMK (\%) & $41(65.1)$ & $9(60)$ & 0.712 \\
\hline NSTE-ACS(\%) & $30(47.6)$ & $10(66.7)$ & 0.185 \\
\hline STEMI (\%) & $33(52.4)$ & $5(33.3)$ & \\
\hline Death (\%) & $2(3.2)$ & $5(33.3)$ & $<0.001$ \\
\hline $\mathrm{BMI} \mathrm{kg} / \mathrm{m}^{2}$ & $26.67(24.22-29.4)$ & $26.56(23.46-27.55)$ & 0.462 \\
\hline Heart rate & $75(65-81)$ & $75(64-86)$ & 0.849 \\
\hline SBP mmHg & $130.0(116.0-150.0)$ & $120.0(100.0-130.0)$ & 0.045 \\
\hline $\mathrm{DBP} \mathrm{mmHg}$ & $80.0(70.0-90.0)$ & $75.0(70.0-80.0)$ & 0.206 \\
\hline $\begin{array}{l}\text { Mean BP } \\
\mathrm{mmHg}\end{array}$ & $96.67(85.67-110.0)$ & 90.67 (80.0-98.0) & 0.103 \\
\hline $\mathrm{Hb} \mathrm{g} / \mathrm{L}$ & $14.6(13.7-15.3)$ & $14(12.7-15.0)$ & 0.165 \\
\hline WBC $\times 10^{9} / \mathrm{L}$ & $9.78(7.88-12.2)$ & $12.8(6.51-15.23)$ & 0.351 \\
\hline $\begin{array}{l}\text { NT-ProBNP } \\
\mathrm{pg} / \mathrm{mL}\end{array}$ & $1018.0(217.7-2567.0)$ & $4746.0(402.1-8519.0)$ & 0.034 \\
\hline $\mathrm{Tnl} \mathrm{ng} / \mathrm{mL}$ & $9.92(0.61-81.56)$ & $11.89(0.19-37.06)$ & 0.596 \\
\hline hs-CRP mg/L & $9.75(3.44-49.9)$ & $13.77(5.67-169.79)$ & 0.29 \\
\hline $\begin{array}{l}\text { Albumin mg/ } \\
\mathrm{dL}\end{array}$ & $3.83(3.6-4.02)$ & $3.82(3.51-4.04)$ & 0.791 \\
\hline $\mathrm{Na}^{+} \mathrm{mmol} / \mathrm{L}$ & $140.0(138.0-142.0)$ & $140.3(136.7-144)$ & 0.817 \\
\hline $\mathrm{K}^{+} \mathrm{mmol} / \mathrm{L}$ & $4.07(3.9-4.3)$ & $4.38(3.93-4.94)$ & 0.101 \\
\hline BUN mg/dL & $16.36(13.3-19.9)$ & $27.18(21.18-38.0)$ & $<0.001$ \\
\hline $\mathrm{HDL} \mathrm{mg} / \mathrm{dL}$ & $35.8(30.08-43.02)$ & $39.38(30.58-49.7)$ & 0.303 \\
\hline LDL mg/dL & 96.63 (79.73-121.86) & $102.52(67.36-111.55)$ & 0.368 \\
\hline T. Chol mg/dL & $160.36(135.68-185.98)$ & 154.19 (122.75-171.27) & 0.274 \\
\hline $\mathrm{TG} \mathrm{mg} / \mathrm{dL}$ & $133.86(102.72-197.1)$ & $105.7(82.74-173.01)$ & 0.159 \\
\hline GRACE & $130(96-152)$ & $156(134-205)$ & 0.002 \\
\hline $\begin{array}{l}\text { Admission } \mathrm{Cr} \\
\mathrm{mg} / \mathrm{dL}\end{array}$ & $0.958(0.75-1.03)$ & $1.346(1.02-1.8)$ & $<0.001$ \\
\hline $\begin{array}{l}\text { Baseline } \mathrm{Cr} \\
\mathrm{mg} / \mathrm{dL}\end{array}$ & $0.803(0.69-0.95)$ & $0.909(0.682-1.084)$ & 0.482 \\
\hline$\Delta \mathrm{Cr} \mathrm{mg} / \mathrm{dL}$ & $0.057(0.0-0.135)$ & $0.411(0.331-0.8)$ & $<0.001$ \\
\hline Max Cr mg/dL & $0.97(0.79-1.14)$ & $1.35(1.03-1.9)$ & $<0.001$ \\
\hline
\end{tabular}

Values are presented in medians and IQR ranges 
In the mediators' analyses, only IL-1 $\beta$ was found increased in the ACS-AKI group ( $p=0.009)$ (Table 2). Serum lipid mediators were found different between patients and controls (see Additional file 1: Table S1). Although inflammation has been recently associated with the development of atrial fibrillation [25], only one of our patients developed such arrhythmia after the ACS; this patient did not develop AKI.

\section{Correlations with $\Delta \mathrm{Cr}$}

The $\Delta \mathrm{Cr}$ had significant positive correlation with BUN (rho $=0.675 p<0.001$ ), admission $\mathrm{Cr}$ (rho $=0.645$ $p<0.001$ ), GRACE (rho $=0.430 p<0.001$ ), IL-1 $\beta$ (rho $=0.335 p=0.003)$, IL-6 (rho $=0.288 p=0.011$ ), NT-ProBNP (rho $=0.257 p=0.029$ ) and age (rho $=0.228$ $p=0.045)$. Negative correlations were found with SBP (rho $=0.29 p=0.01$ ), mean-BP (rho $=-0.283$ $p=0.012$ ), diastolic BP (rho $=-0.267 p=0.018$ ) and LxA4 (rho $=-0.225 p=0.048$ ) (For full correlations see Additional file 2: Table S2).

\section{Generalized additive models in the worsening of renal function}

IL-10 and RvD1 held outstanding results, both had positive non-linear associations with $\Delta \mathrm{Cr}$ [degree of freedom $(d f)=3.344$ and 2.218 respectively] (For all $d f$ values please refer to Table 3). In the case of IL-10 a sigmoidal curve was seen, with 2 sharp positive slopes at $<1-12$ and $>1800 \mathrm{pg} / \mathrm{mL}(\operatorname{logs} 0-2.5$ and 7.5 ) (Fig. 1a); regarding RvD1 the steeper positive slope was seen in levels $>79.45 \mathrm{ng} / \mathrm{mL}(\log 4.375)$ (Fig. 1b). ET-1 had also a positive sigmoidal association with $\Delta \mathrm{Cr}$ $(d f=2.397)$ (Fig. 1c). NT-proBNP $(d f=2.953)$ had 2 sharp positive slopes at the extremes of its concentrations, the first one under $90 \mathrm{pg} / \mathrm{mL}(\log 4.5)$ and the second one over 2980 pg/mL (log 8) (Fig. 1d). Additionally, hs-CRP had a positive relation to $\Delta \mathrm{Cr},(d f)=3.815$, and the slope was steeper in values $>54.6 \mathrm{mg} / \mathrm{L}(\log 4)$ (Fig. 2a).

In the case of the renal related parameters, admission $\mathrm{Cr}$ ( $\mathrm{admCr}$ ) had an additive log-shaped behavior in the model $(d f=3.096)$ (Fig. 2b); BUN had a convoluted regression $(d f=6.031)$ but overall it behaved with a positive slope up to $40 \mathrm{mg} / \mathrm{dL}$, being steeper beyond $30 \mathrm{mg} / \mathrm{dL}$, and becoming negative after $40 \mathrm{mg} / \mathrm{dL}$ (Fig. 2c). Electrolytes also had significant relations to $\Delta \mathrm{Cr}$. In the case of $\mathrm{Na}^{+}$the curve, although complex $(d f=5.501)$, tended to be L-shaped, with a negative relation below $135 \mathrm{mmol} / \mathrm{L}$ (Fig. 2d). $\mathrm{K}^{+}$had a global positive relation $(d f=3.244)$, greater beyond $4.5 \mathrm{mmol} / \mathrm{L}$, however, a slight negative slope was seen in concentrations greater than $5.5 \mathrm{mmol} / \mathrm{L}$ levels (Fig. 3a). In the case of $\mathrm{Hb}$ it had a negative relation to $\Delta \mathrm{Cr}(d f=2.616)$ mainly in levels under $12.5 \mathrm{~g} / \mathrm{dL}$ (Fig. 3b), and white blood count (WBC) in general had a sigmoidal non-linear association $(d f=4.05)$, with the positive slope between 10 and $15 \times 10^{9} / \mathrm{L}$ (Fig. 3c). TnI had also a sigmoidal significant non-linear association $(d f=3.092)$ which describes a steep positive slope in values $>1 \mathrm{ng} / \mathrm{mL}(\log 0)$ (Fig. 3d).

Age had a positive nearly linear relation $(d f=1.349)$ to $\Delta \mathrm{Cr}$ (Fig. 4a). In addition, BMI had also a complex significant relationship $(d f=4.778)$, and in patients with $>35 \mathrm{~kg} / \mathrm{m}^{2}$ a sharp positive curve was seen (Fig. 4b). Mean (Fig. 4c) and SBP (Fig. 4d) both had a stair-shaped relation $(d f=4.43$ and 3.129$)$ and despite the complexity of their behavior, had an overall negative association to $\triangle \mathrm{Cr}$. GRACE score likewise had a non-linear positive relationship to $\Delta \mathrm{Cr}(d f=2.496)$, especially noticeable in scores $>150$ points (Fig. 5).

\section{Protein-protein/chemical interaction and pathways networks analysis}

Protein and chemical interactions are common in vivo; therefore, we performed a network analysis of the

Table 2 Cytokine and lipid mediator analysis

\begin{tabular}{llll}
\hline & ACS & ACS + AKI & $p$ \\
\hline LTB4 pg/mL & $1630.04(1114.72-1968.61)$ & $1711.674(1092.63-1998.27)$ & 0.751 \\
RvD1 ng/mL & $79.02(78.38-79.87)$ & $79.68(78.38-80.6)$ & 0.133 \\
LXA4 pg/mL & $8.1(5.91-9.0)$ & $7.23(4.18-8.59)$ & 0.167 \\
ET-1 pg/mL & $59.82(40.27-80.36)$ & $70.58(33.43-121.42)$ & 0.435 \\
MMP-2 pg/mL & $2497.28(2033.53-3100.16)$ & $2056.72(1871.22-2705.97)$ & 0.068 \\
MMP-9 pg/mL & $4615.7(3103.64-5179.12)$ & $5375.66(3737.82-6030.8)$ & 0.107 \\
TIMP-1 pg/mL & $548.93(420.28-749.69)$ & $544.25(393.57-647.08)$ & 0.428 \\
IL-1 $\beta$ pg/mL & $68.13(0.55-242.91)$ & $400.1(114.01-836.05)$ & 0.009 \\
IL-6 pg/mL & $2399.67(928.71-11,629.24)$ & $10,225.0(1478.48-15,698.29)$ & 0.2 \\
IL-8 pg/mL & $823.52(513.57-1356.21)$ & $958.45(620.41-2292.41)$ & 0.425 \\
IL-10 pg/mL & $743.27(206.63-1390.77)$ & $338.99(197.90-24,162.37)$ & 0.929 \\
\hline
\end{tabular}

Values are medians and IQR ranges 
Table 3 Generalized additive models

\begin{tabular}{|c|c|c|c|}
\hline Variable & Effective $d f$ & F-value & P for smoothed term \\
\hline$\overline{\mathrm{Age}^{\mathrm{a}}}$ & 1.349 & 5.79 & 0.005 \\
\hline BMI & 4.778 & 17.79 & $<0.001$ \\
\hline Heart rate & 1 & 0.89 & 0.348 \\
\hline SBP & 3.129 & 8.52 & $<0.001$ \\
\hline DBP & 1 & 3.87 & 0.06 \\
\hline Mean BP & 4.43 & 11.95 & $<0.001$ \\
\hline $\mathrm{Hb}$ & 2.616 & 13.76 & $<0.001$ \\
\hline WBC & 4.05 & 16.95 & $<0.001$ \\
\hline Admission $\mathrm{Cr}$ & 3.096 & 420.36 & $<0.001$ \\
\hline NT-proBNP & 2.953 & 23.37 & $<0.001$ \\
\hline Tnl & 3.092 & 13.35 & $<0.001$ \\
\hline CRP & 3.815 & 17.81 & $<0.001$ \\
\hline Alb & 1 & 1.22 & 0.274 \\
\hline $\mathrm{Na}$ & 5.501 & 51.95 & $<0.001$ \\
\hline K & 3.244 & 7 & $<0.001$ \\
\hline BUN & 6.031 & 48.61 & $<0.001$ \\
\hline GRACE & 2.496 & 37.57 & $<0.001$ \\
\hline LTB4 & 1 & 0.67 & 0.418 \\
\hline RvD1 & 2.218 & 6.8 & $<0.001$ \\
\hline LxA4 & 1.878 & 2.4 & 0.076 \\
\hline ET1 & 2.397 & 6.73 & $<0.001$ \\
\hline MMP2 & 1 & 0.1 & 0.754 \\
\hline MMP9 & 1 & 2.68 & 0.106 \\
\hline TIMP1 & 1 & 0 & 0.963 \\
\hline IL1b & 1 & 1.91 & 0.171 \\
\hline IL6 & 1 & 1.24 & 0.269 \\
\hline IL8 & 1 & 0.86 & 0.357 \\
\hline IL10 & 3.344 & 9.44 & $<0.001$ \\
\hline
\end{tabular}

Df Degrees of freedom

Model $\Delta C r=$ Predictor + HTN + DM + Type of ACS + Sex + Age

${ }^{a}$ Only included in a partial adjusted analysis (Model $\Delta \mathrm{Cr}=$ Predictor +

HTN + DM + Type of ACS + Sex)

significant variables obtained in this study [IL-1 $\beta$, IL-6, IL-10, NT-ProBNP (nppb), ET-1 (edn-1), CRP, LxA4, $\operatorname{RvD1}, \mathrm{Na}^{+}, \mathrm{K}^{+}, \mathrm{Cr}, \mathrm{BUN}$ (lotion)]. We propose a pathway of predicted protein-protein interactions, based on textmining, experiments, databases, co-expression, neighborhood, gene fusion, co-occurrence and predictions (STITCHv4.0). Using the STITCHv4.0 database we added 10 protein interactors for the final network, these were obtained by initially adding 20 interactors and further removing receptors and chemical components, leaving only non-receptor proteins (all 10 of them had a score > 0.99). The network analysis showed that the current input data had a strong association with the suppressor of cytokine signaling (SOCS)-3, signal transducer and activator of transcription (STAT)-3, STAT-1, JUN, janus kinase (JAK)-2, FOS, IL-18, IL-17A, renin (REN) and caspase (CASP)-1. Furthermore, we used the Enrichment option included in Chemical Disease Interference System [26] (disease analysis) using "acute myocardial infarction" (orange shade) and "acute renal failure" (blue shade) as the search terms. The final proteins in the network were mapped in STITCHv5.0. We added the following edges that weren't available in the STITCHv5.0 network: LxA4-IL1b, LxA-IL6, LxA4IL10, RvD1-IL1b, and IL6-CRP interactions from STITCHv4.0 and EDN1-NPPB from MetaCore ${ }^{\text {Tx }}$. For the final inclusion in the network, the edges were added only after an extensive review and analysis of the available bibliography in each database; these edges are marked in the node location with a black star (Fig. 6).

\section{Discussion}

In the past, the renal dysfunction induced by cardiac injury was mainly explained through hemodynamic changes. Herein we explored associations with diverse mediators and suggest possible inflammatory and neurohormonal pathways in the ACS-AKI context based in our results and on published data. These far from simple pathways that can be traced back to a single triggering insult, are components of complex interaction networks not completely phenotyped yet [4].

\section{Inflammation and immune signaling pathways}

Supporting the notion that an increased inflammation is taking place in the AKI even more so than that seen in ACS alone, IL-1 $\beta$ and IL- 6 were associated to $\Delta C r$. As previously reported $[27,28]$, we found a positive association of IL-6 levels with the worsening of renal function. Previous research in CRS described that higher levels of IL-6 correlate with mortality and kidney injury $[29,30]$. Because of its pleiotropic actions, IL- 6 might be an important crossroad in the cardio-renal talk, one that might account for the hemodynamic, hormonal and immune pathways of the disease. In ACS-AKI, IL-6 may limit tissue loss by inducing anti-apoptotic pathways; however, the continuous IL-6 expression might also lead to deleterious effects via reduced expression of SOCS3 and increased neutrophilic recruitment [31]. Regarding IL- $\beta$ it is increased in plasma of patients with AKI [32], and it is produced by endothelial cells and macrophages in coronary arteries in the ischemic heart disease [33]. IL-1 $\beta$ increases leukocyte infiltration and, together with IL-6, stimulates CRP production [34].

Elevated serum levels of IL-10 had also an important positive association with $\Delta \mathrm{Cr}$. No previous studies have explored the role of IL-10 in the ACS-AKI, but our data agree with previous studies showing that high levels of IL-10 correlate with adverse outcomes in ACS [35] and with the development of AKI after cardiac surgery [36]. 

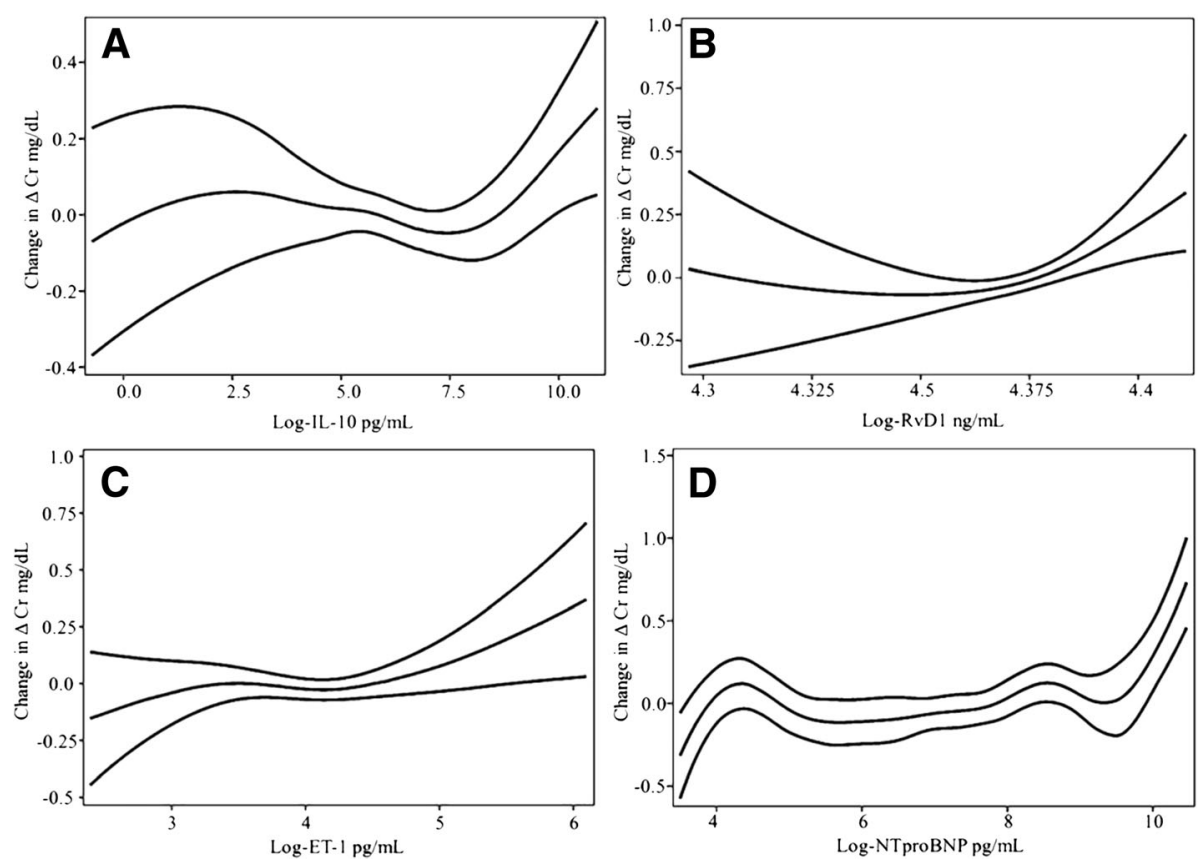

Fig. 1 Some of the most noteworthy interactions in the worsening renal function: IL-10 (a), RvD1 (b), ET-1 (c), NT-proBNP (d), with Cl-95\%

Similarly, raised IL-10 levels in renal dysfunction predict mortality in the acute setting [32]. Nonetheless, it has been shown that IL-10 might protect against AKI by inhibiting the inflammatory cytokines and reducing the leukocyte infiltration [37], and in ACS it can reduce heart dysfunction via chronic STAT-3 activation [38].
Thus, high serum levels of IL-10 seem not to be involved directly with the poor outcomes, but could rather represent a counter action to the heightened inflammatory state in ACS-AKI.

A novel finding presented here, is the one seen with SPMs (RvD1 and LxA4). As far as we could acknowledge,
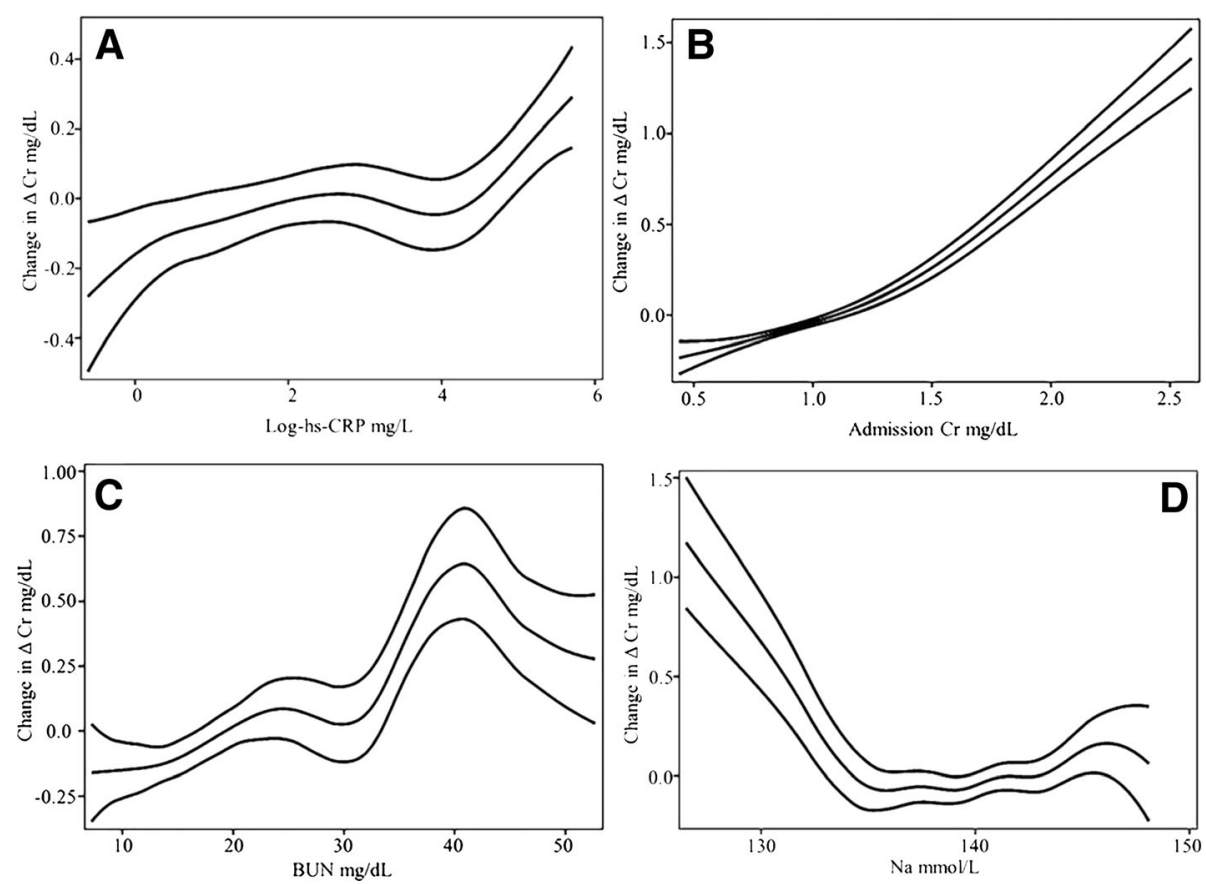

Fig. 2 Generalized additive multivariable models in hs-CRP (a), admission $\mathrm{Cr}(\mathbf{b}), \mathrm{BUN}(\mathbf{c}), \mathrm{Na}+(\mathbf{d})$, with Cl-95\% 

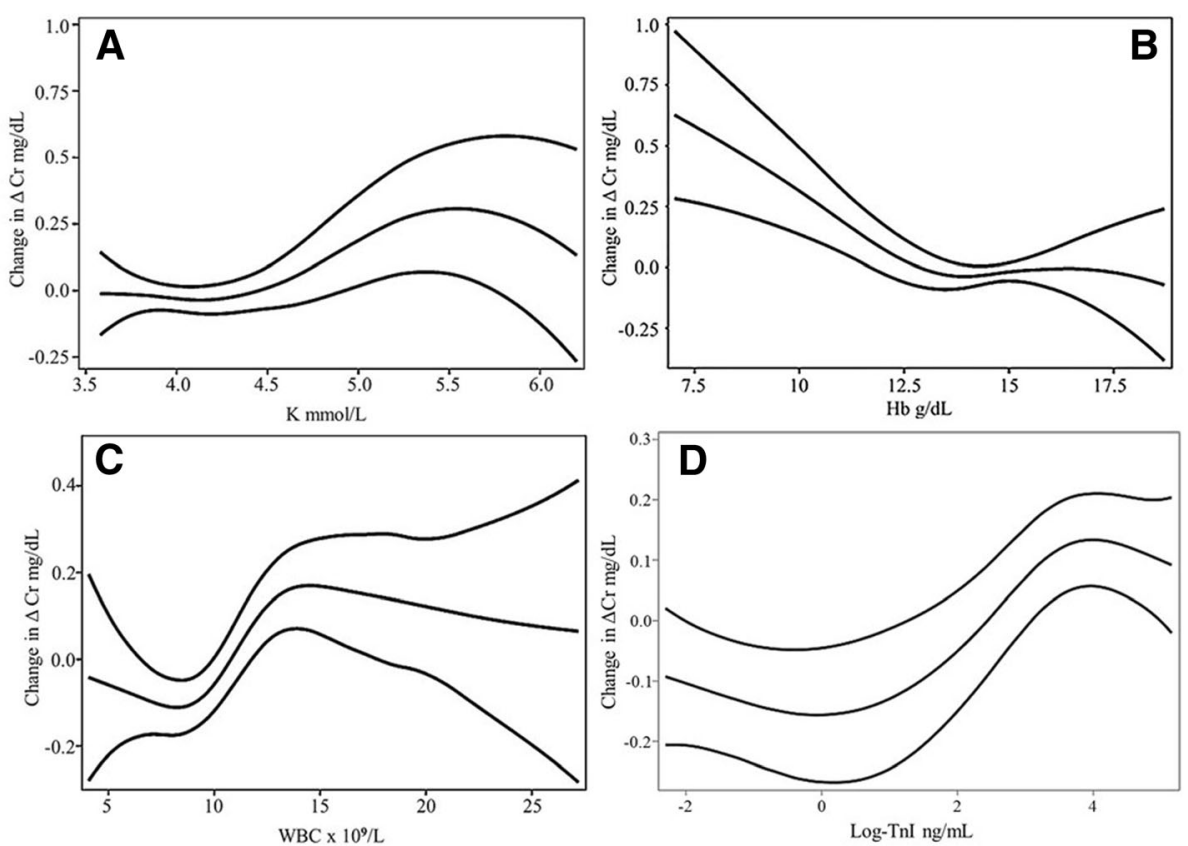

Fig. 3 Generalized additive multivariable models in $\mathrm{K}+(\mathbf{a}), \mathrm{Hb}(\mathbf{b})$, WBC (c), Log-Tnl (d), with Cl-95\%

no study had previously reported human serum levels of these lipid mediators in ACS or AKI. Both have its biological action by halting the damage and clearing apoptotic neutrophils [11]. In our study, overall low SPMs were seen, and LxA4 exhibited a negative correlation with $\Delta \mathrm{Cr}$. Notably, in the regression analysis levels of RvD1were found positively associated with $\Delta \mathrm{Cr}$, however remaining lower than in controls (Additional file 1: Table S1). Recent information from murine models suggests that atherosclerosis is a process with low levels of SPMs, and exogenous administration of RvDs promote the resolution of
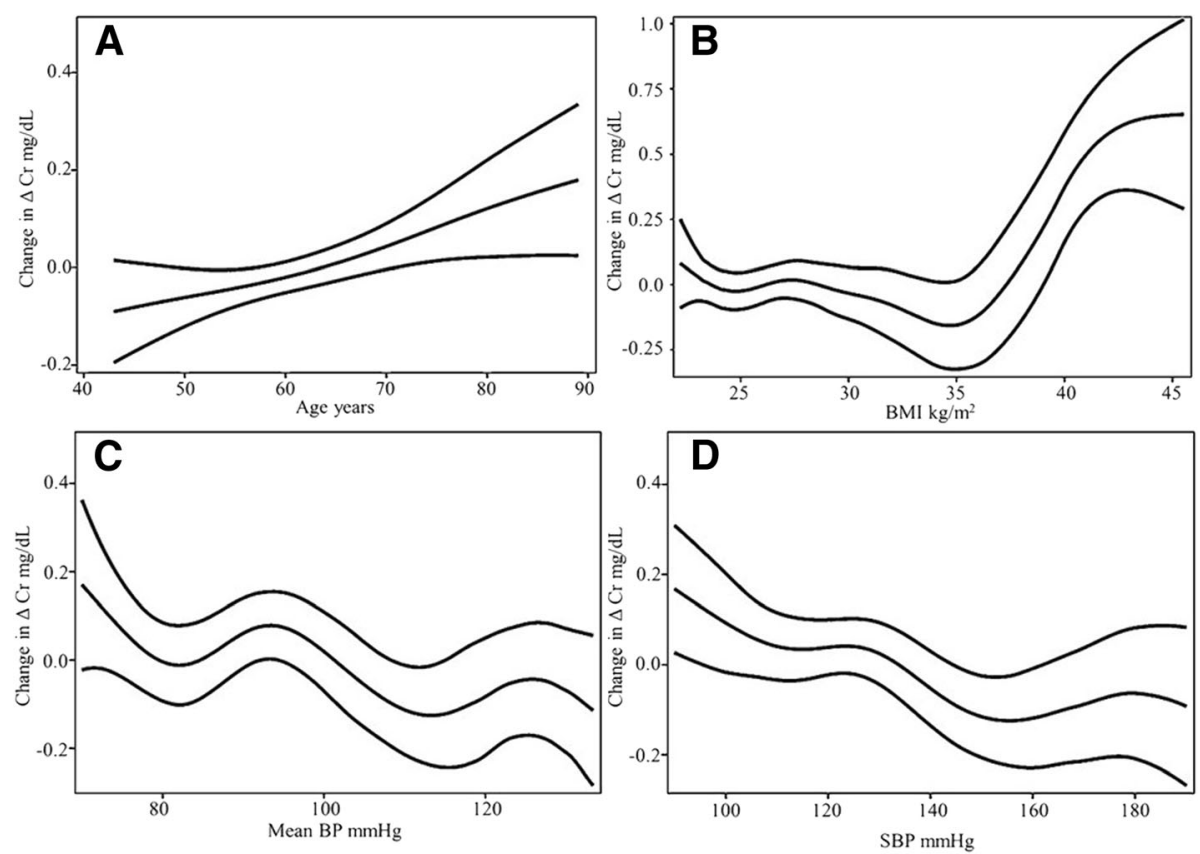

Fig. 4 Generalized additive multivariable models in age (a), BMI (b), Mean BP (c), SBP (d), with Cl-95\% 


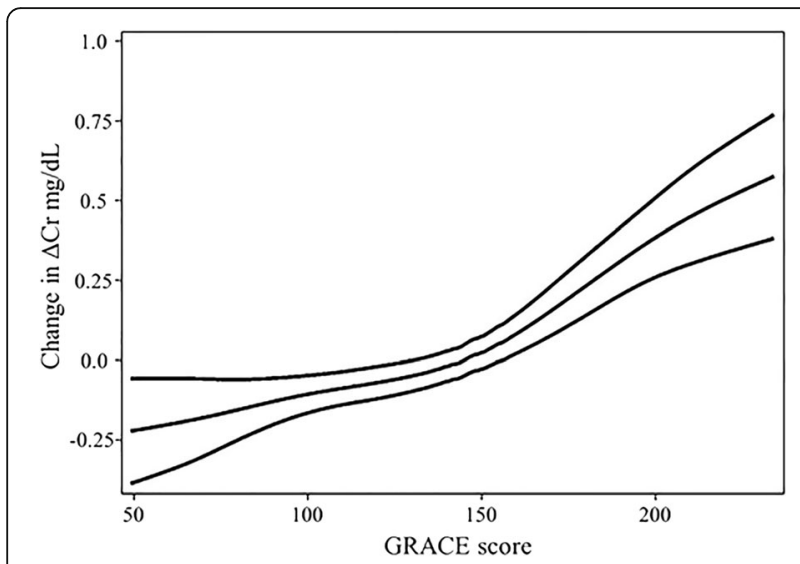

Fig. 5 Generalized additive multivariable models in GRACE, with Cl-95\%

atherosclerotic lesions [39]. In an ischemia reperfusion model in kidney, SPMs suppress fibrosis [11].

Hs-CRP and WBC are no foreigners to the cardiorenal interactions, our results agree with previous studies that show that raised levels of hs-CRP are independent predictors of AKI by impairing tubular epithelium cell regeneration and altering macrophage polarization [40]. Meanwhile, higher WBC seen in CRS patients can lead to neutrophil mediated injury and dysfunction [41].

\section{Hormonal pathway}

NT-proBNP and ET-1 are part of the so-called hormonal pathway. In the current study, both had a positive relationship to $\Delta \mathrm{Cr}$, with the highest values having a steeper slope (Figs. 1d and 2c). ET-1 can increase the production of IL-6; even more it precedes the upregulation of IL-1 $\beta$ and IL- 6 in AHF. ET-1 is also associated in ACS with microvascular obstruction and lower myocardial salvage [42-44]. ET-1 also upregulates NT-proBNP, which is associated with hypotension, hyponatremia and venous congestion [45, 46], variables associated with the hemodynamic explanation of CRS-1. TnI was also found associated to the worsening of renal function in ACS; previous studies demonstrated that AKI alone can raise the levels of $\mathrm{TnI}$ indicating that AKI can also lead to a cardiac injury and that these effects seem to be bidirectional [47].

\section{Hemodynamic pathways}

In our data $\mathrm{Hb}$ had a negative correlation to $\Delta \mathrm{Cr}$ in which a steeper slope was seen in the values $<12.5 \mathrm{~g} / \mathrm{dL}$. Anemia can be part of a dreadful combination in the so call cardio-renal-anemia syndrome since it carries a poorer prognosis, and its prevalence can reach just over $20 \%$ in patients with chronic HF [48]. In addition, GRACE along with some of its elements were significantly associated with $\triangle \mathrm{Cr}$; in previous studies a GRACE $>160$ was related to the development of AKI [49].

\section{Anthropometric factors}

BMI had a significant relation with $\Delta \mathrm{Cr}$ in our study, mainly after $30 \mathrm{~kg} / \mathrm{m}^{2}$. The so called "obesity paradox" has been a point of controversy in ACS [50], but in AKI

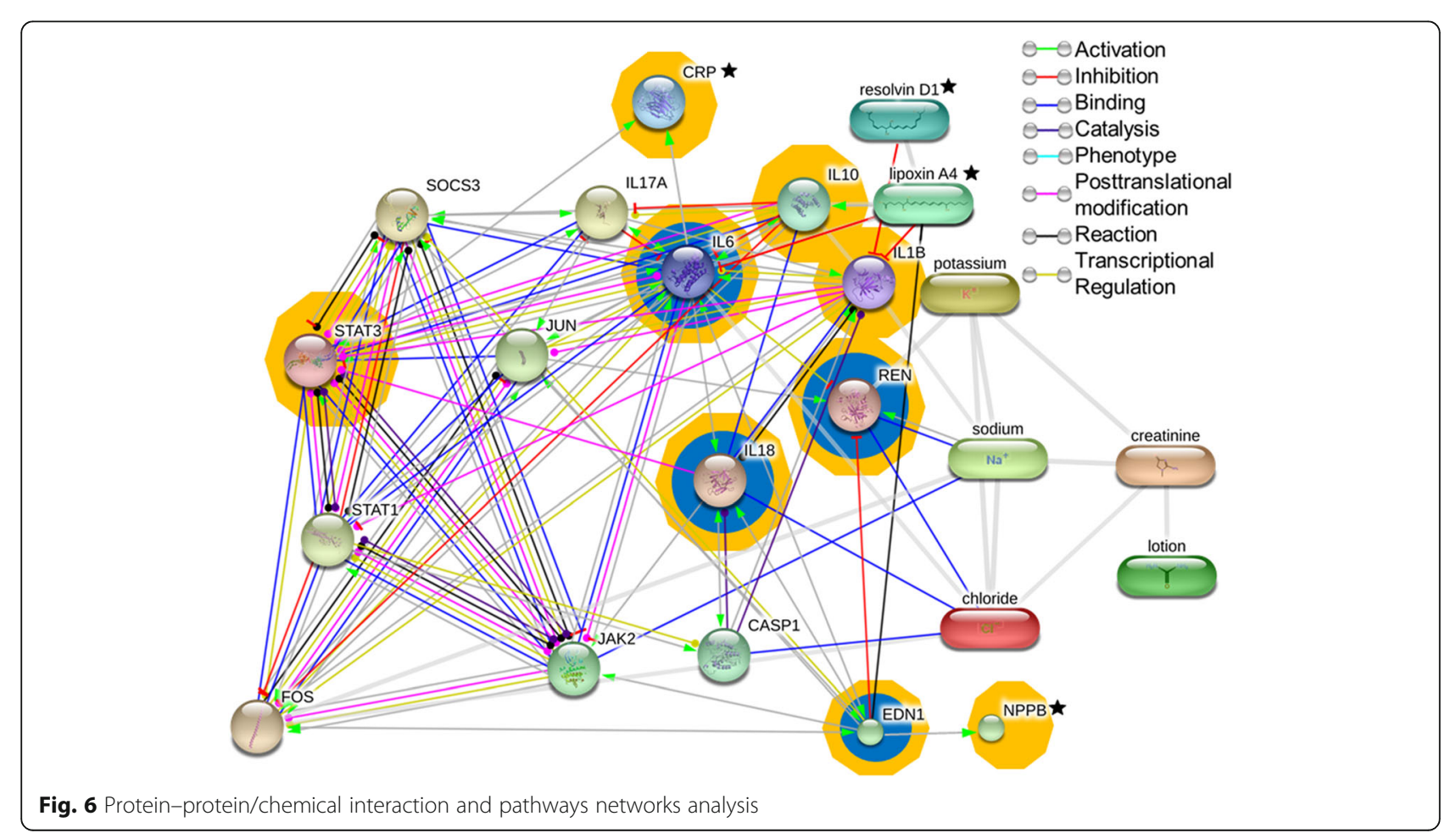


the paradox might not be so, since this and other studies suggest that an increased BMI is a risk factor for developing AKI [51].

\section{Study limitations}

Our study is not exempt of limitations. Previous studies suggest that sampling timing might influence the measurements $[35,52]$, and although the sample was obtained at the time of arrival to the emergency department, and all patients were recruited within the first $24 \mathrm{~h}$ of the initial symptoms, no further subgroup analysis was performed because the study was not designed for this purpose. However, since time of ischemia has been linked to inflammation and renal function [53], it would be interesting to explore whether or not the fact that patients had had previous symptoms of angina, or larger lag periods for initiating therapy, would influence the possible outcome towards AKI. A weakness in our study is the lack of long term outcome data. Also, the associations presented here, although compelling, do not represent causation. Strong points in our study are the fact that it looks at the dynamic changes of $\Delta \mathrm{Cr}$ in ACS-AKI; and that the samples were collected before any invasive procedure, imaging study, diuretic or anti-platelet therapy, thus, precluding their influence on the results as has been demonstrated [54].

\section{Conclusions}

In conclusion, our data suggest that inflammation and its components play an important role in ACS-AKI and the worsening of renal function in the ACS setting. IL10, ET-1, IL-1 $\beta$, TnI, RvD1 and LxA4 represent mediators that might be associated with cardiorenal crosstalk. Furthermore, IL-6, ET-1, NT-ProBNP possibly represent crossroads for several physiopathological pathways involved in "de novo cardiac injury leading to de novo kidney injury".

\section{Additional files}

Additional file 1: Table S1. Results containing the contrast in serum lipid mediator's levels against controls. (DOCX $63 \mathrm{~kb}$ )

Additional file 2: Table S2. Spearman's rank correlations between all studied variables and $\Delta \mathrm{Cr}$. (DOCX $79 \mathrm{~kb}$ )

\footnotetext{
Abbreviations

ACS: Acute coronary syndrome; AHF: Acute heart failure; AKI: Acute Kidney Injury; BP: Blood pressure; BUN: Blood urea nitrogen; CASP: Caspase; Cr: Creatinine; CRS: Cardiorenal syndrome; DBP: Diastolic Blood Pressure; df: Degree of freedom; ET-1: Endothelin-1; Hb: Hemoglobin; HDL: High density lipoprotein; hs-CRP: High-Sensitive C-Reactive-Protein; IL: Interleukin; IQR: Interquartile range; JAK: Janus kinase; $\mathrm{K}+$ : Potassium; LDL: Low density lipoprotein; LTB4: Leukotriene-B4; Lx: Lipoxin; MMP: Matrix metalloproteinase; $\mathrm{Na}+$ : Sodium; NSTE-ACS: Non-ST elevation acute coronary syndrome; NT-proBNP: NT-ProB-Type-Natriuretic-Peptide; REN: Renin; Rv: Resolvin; SBP: Systolic blood pressure; SOCS: Suppressor of cytokine signaling;
}

SPMs: Specialized pro-resolving lipid mediators; STAT: Signal transducer and activator of transcription; STEMI: ST-elevation myocardial infarction; TChol: Total cholesterol; TG: Triglycerides; TIMP: Tissue inhibitor of metalloproteinases; Tnl: Troponin-l; WBC: White blood count; $\Delta \mathrm{Cr}$ : Delta $\mathrm{Cr}$

\section{Acknowledgements}

Not applicable.

\section{Funding}

This research received a specific funding by the Instituto Nacional de Cardiología Ignacio Chávez. No other private or public parties founded the paper or the authors.

\section{Availability of data and materials}

The datasets used and/or analysed during the current study are available from the corresponding author on reasonable request.

\section{Authors' contributions}

$\mathrm{JOH}$ concept, design, data collection, analysis, and interpretation, drafting article. RS laboratory performance and analysis. FSM concept, design, drafting article. JCAM design, data analysis. HGP concept, design, clinical data collection, analysis, and interpretation, drafting article. RB concept, design, data analysis, and interpretation, critical review of the manuscript. All authors read and approved the final manuscript.

\section{Ethics approval and consent to participate}

The study protocol was approved both by the Research Committee and the Ethics in Research Committee of the Instituto Nacional de Cardiología Ignacio Chavez (\#16-971). All patients or their legally authorized representatives provided written informed consent. All procedures were conducted based on the Declaration of Helsinki and local regulations.

\section{Consent for publication}

Not applicable.

\section{Competing interests}

The authors declare that they have no competing interests.

\section{Publisher's Note}

Springer Nature remains neutral with regard to jurisdictional claims in published maps and institutional affiliations.

\section{Author details \\ ${ }^{1}$ Department of Immunology, Instituto Nacional de Cardiología Ignacio Chávez, Juan Badiano 1, Sección XVI, Tlalpan, 14080 Mexico City, Mexico. ${ }^{2}$ Faculty of Medicine, Universidad Nacional Autónoma de Mexico, Avenida Universidad 3000, Copilco-Universidad, 04510 Mexico City, Mexico. ${ }^{3}$ Department of Health Care, Universidad Autónoma Metropolitana Xochimilco, Calzada del Hueso 1100, Villa Quietud, Coyoacán, 04960 Mexico City, Mexico. ${ }^{4}$ Coronary Care Unit, Instituto Nacional de Cardiología Ignacio Chávez, Tlalpan, 14080 Mexico City, Mexico.}

Received: 14 February 2017 Accepted: 20 July 2017

Published online: 26 July 2017

References

1. Pimienta González R, Couto Comba P, Rodríguez Esteban M, Alemán Sánchez JJ, Hernández Afonso J, Rodríguez Pérez MDC, et al. Incidence, mortality and positive predictive value of type 1 Cardiorenal syndrome in acute coronary syndrome. PLoS One. 2016;11(12):e0167166.

2. Ronco C, McCullough P, Anker SD, Anand I, Aspromonte N, Bagshaw SM, et al. Cardio-renal syndromes: report from the consensus conference of the acute dialysis quality initiative. Eur Heart J. 2010;31:703-11.

3. Goldberg A, Kogan E, Hammerman H, Markiewicz W, Aronson D. The impact of transient and persistent acute kidney injury on long-term outcomes after acute myocardial infarction. Kidney Int. 2009;76:900-6.

4. Ronco C, Cicoira M, McCullough PA. Cardiorenal syndrome type 1: pathophysiological crosstalk leading to combined heart and kidney dysfunction in the setting of acutely decompensated heart failure. J Am Coll Cardiol. 2012;60:1031-42. 
5. Hanberg JS, Sury K, Wilson FP, Brisco MA, Ahmad T, Ter Maaten JM, et al. Reduced cardiac index is not the dominant driver of renal dysfunction in heart failure. J Am Coll Cardiol. 2016;67:2199-208.

6. Libby P, Tabas I, Fredman G, Fisher EA. Inflammation and its resolution as determinants of acute coronary syndromes. Circ Res. 2014;114:1867-79.

7. Imig JD, Ryan MJ. Immune and inflammatory role in renal disease. Compr Physiol. 2013;3:957-76.

8. Hsiao P-G, Hsieh C-A, Yeh C-F, Wu H-H, Shiu T-F, Chen Y-C, et al. Early prediction of acute kidney injury in patients with acute myocardial injury. J Crit Care. 2012;27:525.e1-7.

9. Gutiérrez E, Flammer AJ, Lerman LO, Elízaga J, Lerman A, Fernández-Avilés F. Endothelial dysfunction over the course of coronary artery disease. Eur Heart J. 2013;34:3175-81.

10. Guan Z, Inscho EW. Endothelin and the renal vasculature. Contrib Nephrol. 2011;172:35-49.

11. Hong S, Lu Y. Omega-3 fatty acid-derived resolvins and protectins in inflammation resolution and leukocyte functions: targeting novel lipid mediator pathways in mitigation of acute kidney injury. Front Immunol. 2013;4:13.

12. Kain V, Ingle KA, Colas RA, Dalli J, Prabhu SD, Serhan CN, et al. Resolvin D1 activates the inflammation resolving response at splenic and ventricular site following myocardial infarction leading to improved ventricular function. J Mol Cell Cardiol. 2015;84:24-35.

13. Núñez J, Núñez E, Miñana G, Bayés-Genis A, Sanchis J. Worsening renal function in acute decompensated heart failure. JACC Heart Fail. 2016;4:232-3.

14. Amsterdam EA, Wenger NK, Brindis RG, Casey DE, Ganiats TG, Holmes DR, et al. 2014 AHA/ACC guideline for the Management of Patients with nonST-elevation acute coronary syndromes: a report of the American College of Cardiology/American Heart Association task force on practice guidelines. Circulation. 2014;130:e344-426.

15. O'Gara PT, Kushner FG, Ascheim DD, Casey DE, Chung MK, de Lemos JA et al. 2013 ACCF/AHA guideline for the management of ST-elevation myocardial infarction. J Am Coll Cardiol. 2013;61:e78-140.

16. Cannon CP, Battler A, Brindis RG, Cox JL, Ellis SG, Every NR, et al. American College of Cardiology key data elements and definitions for measuring the clinical management and outcomes of patients with acute coronary syndromes. A report of the American College of Cardiology Task Force on clinical data standards (acute Coro). J Am Coll Cardiol. 2001;38:2114-30.

17. KDIGO. Clinical practice guideline for acute kidney injury. Kidney Int Suppl. 2012;2:1-138

18. Crawford SL. Correlation and regression. Circulation. 2006;114:2083-8.

19. Altman DG. The cost of dichotomising continuous variables. BMJ. 2006:332:1080

20. Wood SN. Low-rank scale-invariant tensor product smooths for generalized additive mixed models. Biometrics. 2006;62:1025-36.

21. Wood SN. On p-values for smooth components of an extended generalized additive model. Biometrika. 2013;100:221-8.

22. Szklarczyk D, Franceschini A, Wyder S, Forslund K, Heller D, Huerta-Cepas J, et al. STRING v10: protein-protein interaction networks, integrated over the tree of life. Nucleic Acids Res. 2015:43:D447-52.

23. Kuhn M, Szklarczyk D, Pletscher-Frankild S, Blicher TH, von Mering C, Jensen $\sqcup$, et al. STITCH 4: integration of protein-chemical interactions with user data. Nucleic Acids Res. 2014;42:D401-7.

24. Szklarczyk D, Santos A, von Mering C, Jensen LJ, Bork P, Kuhn M. STITCH 5: augmenting protein-chemical interaction networks with tissue and affinity data. Nucleic Acids Res. 2016:44:D380-4

25. Bas HA, Aksoy F, Icli A, Varol E, Dogan A, Erdogan D, et al. The association of plasma oxidative status and inflammation with the development of atrial fibrillation in patients presenting with ST elevation myocardial infarction. Scand J Clin Lab Invest. 2017;77:77-82.

26. Tung C-W. ChemDIS: a chemical-disease inference system based on chemical-protein interactions. J Cheminform. 2015;7:25

27. Pastori S, Virzì GM, Brocca A, de Cal M, Clementi A, Vescovo G, et al. Cardiorenal syndrome type 1: a defective regulation of monocyte apoptosis induced by proinflammatory and proapoptotic factors. Cardiorenal Med. 2015;5:105-15.

28. Virzì GM, Torregrossa R, Cruz DN, Chionh CY, de Cal M, Soni SS, et al. Cardiorenal syndrome type 1 may be immunologically mediated: a pilot evaluation of monocyte apoptosis. Cardiorenal Med. 2012;2:33-42.

29. Cho E, Kim MMG, Ko YS, Lee HY, Song M, Kim MMG, et al. Role of inflammation in the pathogenesis of cardiorenal syndrome in a rat myocardial infarction model. Nephrol Dial Transplant. 2013;28:2766-78.
30. Musleh GS, Datta SS, Yonan NN, Grotte GJ, Prendergast BA, Hasan Rl, et al. Association of IL6 and IL10 with renal dysfunction and the use of haemofiltration during cardiopulmonary bypass. Eur J Cardiothorac Surg 2009:35:511-4.

31. Fontes JA, Rose NR, Čiháková D. The varying faces of IL-6: from cardiac protection to cardiac failure. Cytokine. 2015;74:62-8.

32. Simmons EM, Himmelfarb J, Sezer MT, Chertow GM, Mehta RL, Paganini EP, et al. Plasma cytokine levels predict mortality in patients with acute renal failure. Kidney Int. 2004;65:1357-65.

33. Galea J, Armstrong J, Gadsdon P, Holden H, Francis SE, Holt CM. Interleukin$1 \beta$ in coronary arteries of patients with ischemic heart disease. Arterioscler Thromb Vasc Biol. 1996;16:1000-6.

34. Dinarello CA, Simon A, van der Meer JWM. Treating inflammation by blocking interleukin-1 in a broad spectrum of diseases. Nat Rev Drug Discov. 2012;11:633-52.

35. Cavusoglu E, Marmur JD, Hojjati MR, Chopra V, Butala M, Subnani R, et al. Plasma interleukin-10 levels and adverse outcomes in acute coronary syndrome. Am J Med. 2011;124:724-30.

36. Zhang WR, Garg AX, Coca SG, Devereaux PJ, Eikelboom J, Kavsak P, et al. Plasma IL-6 and IL-10 concentrations predict AKI and long-term mortality in adults after cardiac surgery. J Am Soc Nephrol. 2015;26:3123-32.

37. Milwid JM, Ichimura T, Li M, Jiao Y, Lee J, Yarmush JS, et al. Secreted factors from bone marrow stromal cells upregulate IL-10 and reverse acute kidney injury. Stem Cells Int. 2012;2012:1-12.

38. Frangogiannis NG. Regulation of the inflammatory response in cardiac repair. Circ Res. 2012;110:159-73.

39. Viola JR, Lemnitzer P, Jansen Y, Csaba G, Winter C, Neideck C, et al. Resolving lipid mediators Maresin 1 and Resolvin D2 prevent Atheroprogression in mice. Circ Res. 2016;119:1030-8.

40. Pegues MA, McCrory MA, Zarjou A, Szalai AJ. C-reactive protein exacerbates renal ischemia-reperfusion injury. Am J Physiol Renal Physiol. 2013:304:F1358-65.

41. Weylandt KH, Chiu CY, Gomolka B, Waechter SF, Wiedenmann B. Omega-3 fatty acids and their lipid mediators: towards an understanding of resolvin and protectin formation. Prostaglandins Other Lipid Mediat. 2012:97:73-82.

42. Gerstung M, Roth T, Dienes H-P, Licht C, Fries JWU. Endothelin-1 induces NF-kB via two independent pathways in human renal tubular epithelial cells. Am J Nephrol. 2007;27:294-300.

43. Yang LL. Conditional cardiac overexpression of endothelin-1 induces inflammation and dilated cardiomyopathy in mice. Circulation. 2004;109:255-61.

44. Freixa X, Heras M, Ortiz JT, Argiró S, Guasch E, Doltra A, et al. Utilidad de la determinación de endotelina-1 en el infarto agudo de miocardio. Rev Española Cardiol. 2011;64:105-10.

45. Testani JM, Damman K, Brisco MA, Chen S, Laur O, Kula AJ, et al. A combined-biomarker approach to clinical phenotyping renal dysfunction in heart failure. J Card Fail. 2014;20:912-9.

46. Kerkelä R, Pikkarainen S, Majalahti-Palviainen $T$, Tokola $H$, Ruskoaho $H$ Distinct roles of mitogen-activated protein kinase pathways in GATA-4 transcription factor-mediated regulation of B-type natriuretic peptide gene. J Biol Chem. 2002;277:13752-60.

47. Song D, de Zoysa JR, Ng A, Chiu W. Troponins in acute kidney injury. Ren Fail. 2012;34:35-9.

48. Scrutinio D, Passantino A, Santoro D, Catanzaro R. The cardiorenal anaemia syndrome in systolic heart failure: prevalence, clinical correlates, and longterm survival. Eur J Heart Fail. 2011;13:61-7.

49. Liu YHYYH, Liu YHYYH, Tan N, Chen JJJ, Chen JJJ, Chen S, et al. Predictive value of GRACE risk scores for contrast-induced acute kidney injury in patients with ST-segment elevation myocardial infarction before undergoing primary percutaneous coronary intervention. Int Urol Nephrol. 2014;46:417-26.

50. Niedziela J, Hudzik B, Niedziela N, Gąsior M, Gierlotka M, Wasilewski J, et al. The obesity paradox in acute coronary syndrome: a meta-analysis. Eur J Epidemiol. 2014;29:801-12.

51. Danziger J, Chen KP, Lee J, Feng M, Mark RG, Celi LA, et al. Obesity, acute kidney injury, and mortality in critical illness. Crit Care Med. 2016;44:328-34.

52. Mälarstig A, Eriksson P, Hamsten A, Lindahl B, Wallentin L, Siegbahn A. Raised interleukin-10 is an indicator of poor outcome and enhanced systemic inflammation in patients with acute coronary syndrome. Heart. 2008;94:724-9. 
53. D'Ascenzo F, Moretti C, Omedè P, Cerrato E, Cavallero E, Er F, et al. Cardiac remote ischaemic preconditioning reduces periprocedural myocardial infarction for patients undergoing percutaneous coronary interventions: a meta-analysis of randomised clinical trials. Eurolntervention. 2014;9:1463-71.

54. D'Ascenzo F, Moretti C, Bianco M, Bernardi A, Taha S, Cerrato E, et al. Metaanalysis of the duration of dual antiplatelet therapy in patients treated with second-generation drug-eluting stents. Am J Cardiol. 2016;117:1714-23.

Submit your next manuscript to BioMed Central and we will help you at every step:

- We accept pre-submission inquiries

- Our selector tool helps you to find the most relevant journal

- We provide round the clock customer support

- Convenient online submission

- Thorough peer review

- Inclusion in PubMed and all major indexing services

- Maximum visibility for your research

Submit your manuscript at www.biomedcentral.com/submit
Biomed Central 